\title{
Status of Divine Word Colleges in Region 1, Philippines
}

\author{
Maria Veronica Callanta-Fontanilla, Ed. D. \\ Hanseo University, South Korea \\ dr_nikkifontanilla@yahoo.com
}

\begin{abstract}
This study aimed to determine the status of Divine Word Colleges in Region I, Philippines, with the use of a self-devised questionnaire. Majority are 31 - 40 years old, females, married, Bachelor's degree holders with units in the Master's program, ranked instructor I-IV with 1-10 years of working experience and with monthly salary of Php. 9,001-12,000. Majority of the students are taking up Nursing, aged 19-22 years and females. In terms of the status of the colleges along ten dimensions, an overall descriptive rating of 'high' was achieved. There is a significant difference existing between the colleges with eight variables except instruction and library. A relationship exists between civil status and the variables among the administrators, and between highest educational attainment of the respondents and faculty. On the other hand, a negligible and direct perfect degree of relationship was obtained along monthly salary and non-teaching staff variables.
\end{abstract}

Keywords: Divine Word Colleges, Philippines, Region 1, Status

\section{Introduction}

Among the tertiary catholic private schools established in the Philippines, the Divine Word Colleges are making waves. As catholic institutions, they aim of putting Christ as the center of every academic endeavor, with greater emphasis on quality education. Divine Word Colleges are found on Christian principles which cater to the needs of modern men, as manifested by a flexible and service-oriented academe composed of the administration, faculty and support staff of the society of the Divine Word (SVD). SVD schools are scattered in the Philippines. In region I, these private tertiary institutions comprise the Divine Word College of Loaog in Ilocos Norte, Divine Word College of Vigan in Ilocos Sur, and Divine Word College of Urdaneta in Pangasinan. This Divine Word Colleges in the North respond to the needs of the people providing socially-responsive programs and innovative curricula, which are just some of the primary considerations for education. The present political and economic crisis, however, has created an impact to quality education. The soaring prices of petroleum products, uncontrolled vehicular fares and devaluating peso, have, more or less, created a drastic effect in the educational system, most particularly among private tertiary institutions like the Divine Word Colleges. Admittedly, this unwanted scenarios, have direct and indirect effect on the clienteles, the students, who take the main role in the education field.

In view of this, it is imperative that educational institutions, like the Divine Word Colleges, must see to it that they meet the stringent requirements for quality education as set by the Commission of Higher Education (CHED). Findings of this study may pave the way for SVD administrators to integrate effective strategies for the growth and development of their respective schools to improve policies in administration and supervision;

- For the teaching personnel, for them to determine their strength and weaknesses in instruction, and further analyze their important roles as agents of change for development

- For the non-teaching personnel, that they may be able to become partners in the delivery of services to the clienteles, and that, for them to realize their significant roles in the implementation of policies, goals and objectives of their institutions

- Finally, to the students, for them to realize the importance of education, and the effect of their being enrolled in private educational institutions

Statement of the Problem: This study looked into the status of Divine Word Colleges in Region I. It sought to answer the following questions:

a) What is the profile of the personnel-respondents in terms of their: 
- age,

- gender,

- civil status,

- higher educational attainment,

- rank,

- length of working experience in the institutional, and

- monthly salary?

b) What is the profile of the student-respondents in terms of their:

- age,

- $\quad$ gender, and

- course?

- What is the status of Divine Word Colleges in Region I in terms of :

- purposes and objectives,

- instruction,

- faculty,

- research,

- extension services,

- library,

- laboratory,

- $\quad$ physical plant and facilities,

- student services, and

- administration?

c) Is there a significant difference in the status of Divine Word Colleges in Region I by school along?

- $\quad$ purposes and objectives,

- instruction,

- faculty,

- research,

- extension services,

- library,

- laboratory,

- physical plant and facilities,

- $\quad$ student services, and

- administration?

d) Is there a significant relationship between the status of Divine Word Colleges in Region I and the

- Administrator-related factors,

- Faculty-related factors, and

- Non-teaching staff-related factors?

\section{Methodology}

Research Design: This study has utilized the descriptive method of research. As cited by [1] Domingo (1999), descriptive research involves collection of data in order to test hypotheses or to answer questions concerning the current status of the subject of the study.

Population and Sample: Tertiary administrators, faculty, non-teaching personnel and graduating students of the Divine Word College of Laoag (DWCL-Laoag City, Ilocos Norte), Divine Word College of Vigan (DWCVVigan City, Ilocos Sur) and Divine Word College of Urdaneta (DWCU-Urdaneta City, Pangasinan) were taken as respondents. (Please refer to Table 1 in the Appendices)

Data Gathering Instrument: A self-employed data gathering questionnaire-checklist was employed in gathering the data needed in this study. The questions in the checklist dealt on the determination of the status of Divine word Colleges in Region I in the different areas, namely Purposes and Objectives, Instruction, Faculty, Research, Extension Services, Library, Laboratory, Physical Plant and Facilities, Student Services and 
Administration. The tertiary administrators, faculty and non-teaching personnel of the Divine Word College of Vigan, Divine Word College of Laoag, and Divine Word College of Urdaneta, served as the respondents of the study. The first part of the questionnaires elicited information of the profile of the respondents as regard to their age, gender, civil status, highest educational attainment, rank, length of working experience and monthly salary. The second parts of the questionnaire comprise the different areas or dimensions, which served as the gauge in measuring the status of the above-mentioned status of Divine Word Colleges in Region I. The items that were included in the questionnaire were based from the PAASCU manual, while the rest of the questions, were formulated by the researcher.

Statistical Treatment of Data: The data that were gathered in this research were treated statistically in the following manner:

- The responses to the questionnaire of the respondents were tallied and analyzed using tables of frequencies and percentages.

- Weight Mean was used to determine the status of the Divine Word Colleges in Region I along purposes and objectives, instruction, faculty, research, extension services, library, laboratory, physical plant and facilities, student services and administration.

- One-factor Analysis of Variance (ANOVA) was utilized to determine the differences in the status of the three Divine Word Colleges in Region along the above-mentioned dimensions. Scheffe' test was further utilized to determine school efficiency.

- Simple Linear Correlation Analysis was used to determine the relationship of the profile of the respondents and the different dimensions like purposes and objectives, instruction, faculty, research, extension services, library, laboratory, physical plant and facilities, student services and administration.

Summary: This study attempted to determine the status of the Divine Word Colleges in Region I. Specially, it sought to answer the following questions:

a) What is the profile of the personnel-respondents in terms of their?

- age,

- gender,

- civil status,

- highest educational attainment,

- rank,

- length of working experience in the institution, and

- monthly salary?

b) What is the profile of the student-respondents in terms of their:

- age,

- gender, and

- course?

c) What is the status of the Divine Word Colleges in Region I along?

- Purposes and Objectives,

- Instruction,

- Faculty,

- Research,

- Extension Services,

- Library,

- Laboratory,

- Physical Plant and Facilities,

- Student Services and,

- Administration?

d) Is there a significant difference in the status of the Divine Word Colleges in Region I by school along?

- Purposes and Objectives,

- Instruction,

- Faculty,

- Research, 
- Extension Services,

- Library,

- Laboratory,

- Physical Plant and Facilities,

- Student Services and,

- Administration?

e) Is there a significant relationship between the status of the Divine Word Colleges in Region I and the

- administrator-related factors,

- faculty-related factors, and

- non-teaching staff-related factors?

\section{Findings}

Based on the data gathered, the following are obtained:

1. On the profile of the Personnel-Respondents (Please refer to Table $2 \mathrm{n}$ the Appendices): Majority of the respondents is between the age ranges of 31-40, most of them are females, many are married, while majority are bachelor's degree holders. On the other hand, many among the respondents are ranked as Instructor 1-4, majority have 1-10 years of working experience and many are receiving Php. 9,000 - 12,001 in terms of salary.

2. On the profile of the Student-Respondents (Please refer to Table 3 in the Appendices): Majority of the student-respondents is within the age range of 19-21, many are females and most of them are graduating nursing students.

3. On the status of the Divine Word Colleges along: (Please refer to Table 4 in the Appendices)

a. Purposes and Objectives. DWCV got an overall mean of 3.96, which is "high"; DWCL has 3.99 (high) while DWCU has 3.19 (fair). As a whole, a mean of 3.92 was calculated which is "high".

b. Instruction. A mean of 3.90 (High) was calculated for DWCV and 3.95 (high) for DWCL. Meanwhile, DWCU got a mean of 3.71 (high). As a whole, a mean of 3.92 (high) was achieved by the three colleges.

c. Faculty. A 3.94 (high) mean for DWCV and DWCL has achieved, 3.94, while a "fair" mean of 3.36 was obtained by DWCU. A mean of 3.91 (high) was calculated by the three colleges, as a whole.

d. Research. Along this area, a mean of 3.72 (high) was attained by DWCV; DWCL has 3.87 (high), while DWCU got a very low mean of 2.36. However, a mean of 3.73 (high) was attained for this item as a whole.

e. Extension Services. A descriptive rating of "high" was attained by DWCV, with a mean of 3.77; DWCL has 4.00 (high) while a "low" rating was achieved by DWCU with 2.78 mean. As a whole, a mean of 3.73 was attained.

f. Library. The overall mean for DWCV is 3.74 (high), while DWCL has 3.92 (high). On the other hand, DWCU has 3.62 mean which is "high". As a whole, a mean of 3.85 (high) was obtained.

g. Laboratory. A 3.78 mean was obtained by DWCV, while a mean of 3.85 was achieve by DWCL (high). On the other side, DWCU achieved a mean of 3.26 (high). As a whole, a 3.78 mean was obtained.

h. Physical Plant and Facilities. DWCV got a mean of 3.80 (high); DWCL has 3.98 (high) while DWCU has 3.59. as a whole, a "high" mean of 3.90 was attained.

i. Student Services. A mean of 3.88 (high) was achieved by DWCV; DWCL has 4.00 (high), while DWCU has 3.31 (fair). As a whole, a mean of 3.91, was attained by the three colleges.

j. Administration. A 4.03 (high) mean was calculated by DWCV, 3.78 (high) mean by DWCL and 2.75 (fair) by DWCU. As a whole, a mean of 3.70 (high) was attained.

The summary of the status of the Divine Word Colleges in region I reflects an overall rating of 3.83 (high) for DWCV, 3.92 (high) for DWCL and a "fair" 3.31 rating for DWCU. As a whole, a mean of 3.85 (high) was obtained by the three colleges along the ten dimensions mentioned above.

It can be gleaned in the table, however that a "fair" descriptive rating was achieved by DWCU along research. This could be due to the fact that there is no intensified research program implemented by the school.

4. On the significant difference in the status of the Divine Word Colleges in Region I along: (Please refer to Table 5 in the Appendices) 
a. Purposes and Objectives. A significant difference exists between the colleges in Region I and the dimension cited. This had led to the rejection of the null hypothesis.

b. Instruction. No significant difference exists between the Divine Word Colleges in region I along this area. With this, the null hypothesis is accepted.

c. Faculty. A significant difference exists between the colleges in region I. As exhibited by its significance at 0.05 level. Therefore the null hypothesis is rejected.

d. Research. There is a significant difference between the colleges in terms of this dimension. The t-probability is lesser than 0.05 , therefore, the null hypothesis is rejected.

e. Extension Services. A significant difference exists between the colleges as exhibited by the rejection of the null hypothesis tested at 0.05 level of significance.

f. Library. No significant difference exists between the colleges as exhibited by the acceptance of the null hypothesis where t-probability was tested at 0.05 level of significance.

g. Laboratory. There is a significant difference existing between the colleges as exhibited by the acceptance of the null hypothesis. The t-probability was tested at 0.05 level of significance.

h. Physical Plant and Facilities. A significant difference was found to exist between the colleges. The t-probability was tested at 0.05 level of significance; therefore, the null hypothesis was rejected.

i. Student Services. There is a significant difference between the colleges along this area and their status. This has therefore led to the rejection of the null hypothesis which was tested at 0.05 level.

j. Administration. A significant difference exists between the colleges along this dimension and their status. The null hypothesis was rejected tested at 0.05 level of significance.

5. On the Significant Relationship between the status of the Divine Word Colleges of Region I and the administrator related factors: No significant relationship was found to exist between the status of the Divine Word Colleges in Region I and the administrator-related variables, namely age, gender, civil status, highest educational attainment, rank, working experience and monthly salary.

6. On the Significant Relationship between the status of the Divine Word Colleges of Region I and the Teacher-related factors: No significant relationship was found to exist between the status of the Divine Word Colleges in Region I and the teacher-related variables cited above.

7. On the Significant Relationship between the status of the Divine Word Colleges of Region I and the Non-Teaching Staff-related factors: No significant relationship was found to exist between the status of the colleges with the non-teaching staff related variables but there exists a significant relationship between sex and administration and highest educational attainment and library.

4. Recommendations: Based on the data gathered, the following are highly recommended:

- More personnel should be motivated to undergo post-graduate studies. This will help them become abreast with the trends in education for professional and personal growth.

- Marketing of courses should be conducted so as to attract more students to enroll, especially in the Divine Word College of Urdaneta, Pangasinan, Philippines where enrolment is low.

- Research as an area should be intensified, as well as the conduct of more extension services not only in the school community but also outside the school community. Further, more budget should be allocated to meet the projects and activities of the program.

- The Divine Word College of Urdaneta, Pangasinan, Philippines, should look into the possibility of opening a research program that will look into the needs of the community. In this way, research findings will be promptly reported and presented in conferences and/or symposia. Apart from this, it has to consider the possibility of going into accreditation to further improve in the different areas of concern. More male personnel should be encouraged in the administrative task. Male administrators are more firm and decisive in terms of organizational problems.

\section{References}

Domingo, A. C. (1999). Environmental Awareness And Practices of The Administrators and Students of Selected Universities and Colleges Of Region I-III", Unpublished Dissertation, University of Northern Philippines, Vigan City. 